\title{
Innate Immunity and Chronic Obstructive Pulmonary Disease: A Mini-Review
}

\author{
Renat Shaykhiev Ronald G. Crystal \\ Department of Genetic Medicine, Weill Cornell Medical College, New York, N.Y., USA
}

\section{Key Words}

Airway epithelial barrier - Alveolar macrophages - Chronic obstructive pulmonary disease $\cdot$ Dendritic cells $\cdot$ Innate immunity - Natural killer cells $\cdot$ Neutrophils

\begin{abstract}
Chronic obstructive pulmonary disease (COPD), a major smoking-associated lung disorder characterized by progressive irreversible airflow limitation, affects $>200$ million people worldwide. Individuals with COPD have increased susceptibility to respiratory infections, resulting in exacerbations of the disease. A growing body of evidence indicates that multiple host defense mechanisms, such as those provided by the airway epithelial barrier and innate immune cells, including alveolar macrophages, neutrophils, dendritic cells and natural killer cells, are broadly suppressed in COPD in a smoking-dependent manner. Inactivation of the innate immune system observed in COPD smokers is remarkably similar to the immunosenescence phenotype associated with aging. As a consequence of defective innate immune defense, the lungs of COPD smokers are frequently colonized with pathogens and commonly develop bacterial and viral infections, which cause secondary inflammation, a major driver of the disease progression. In this review, we summarize the evidence from human studies related to disordering of the innate immune system in COPD, discuss possible relationships between those changes and aging, and provide insights into potential therapeutic strategies aimed at the prevention of COPD progression via normalization of the disordered innate immune mechanisms.

(c) 2013 S. Karger AG, Basel
\end{abstract}

Chronic obstructive pulmonary disease (COPD) affects $>200$ million people worldwide, representing a significant healthcare problem, especially among the elderly. Cigarette smoking, the major risk factor for COPD, causes structural and functional alterations in the airways and alveolar region of the lung, leading to progressive irreversible airflow limitation, the hallmark of COPD [1]. Although it has been postulated that COPD develops as a result of an exaggerated inflammatory response of the lung to cigarette smoking, the primary mechanisms responsible for smoking-induced COPD pathogenesis remain unclear. Existing anti-inflammatory therapies neither cure COPD nor are fully effective in controlling COPD progression once the disease is established, suggesting that mechanisms other than inflammation play an important role in the pathogenesis of COPD. Since $20-25 \%$ of COPD patients have no history of cigarette smoking, other factors, such as exposure to occupational pollutants, previous respiratory diseases and other chronic diseases, altered micronutrient status, alcoholism, obesity, limited physical activity, as well as aging may be important for the derangement of lung structure, function and innate immunity in some COPD patients $[1,2]$.

One common feature of COPD is increased susceptibility to respiratory infections [3]. While the respiratory tract and lung parenchyma are sterile in healthy individuals, pulmonary colonization with various bacteria such as Haemophilus influenzae, Streptococcus pneumonia and Moraxella catarrhalis is found in up to $30 \%$ of COPD patients with stable disease and in more than $50 \%$ of patients during COPD exacerbations [3]. The lower respiratory

\section{KARGER}

E-Mail karger@karger.com

www.karger.com/ger
(C) 2013 S. Karger AG, Basel

0304-324X/13/0596-0481\$38.00/0
Ronald G. Crystal, MD

Department of Genetic Medicine, Weill Cornell Medical College

1300 York Avenue, Box 164

New York, NY 10065 (USA)

E-Mail geneticmedicine@med.cornell.edu 
tract of COPD patients with no symptoms of infection exhibits remarkable microbiome diversity with patterns of enriched bacteria different from those detected in the proximal airways [4]. Given that small airways represent the primary anatomic site of pathological changes associated with the development of COPD [1], it is possible that a distinct type of host-microbe interactions initiated in the distal respiratory tract of COPD patients plays a role in the progression of the disease. In this context, the frequency of bacterial colonization and frank infection strongly correlate with the disease severity [3].

Respiratory viruses, which can be detected in more than $10 \%$ of individuals with stable COPD and about $50 \%$ of patients experiencing exacerbations, represent another important cause of COPD exacerbations [3,5]. Rhinovirus is the most frequently detected virus in the respiratory tract of COPD patients, followed by the influenza virus and respiratory syncytial virus [5]. COPD patients infected with rhinovirus showed more severe symptoms, airway obstruction and higher viral load than healthy smokers [6].

Together, the evidence supports the concept that microbial colonization and respiratory infection represent important factors in the pathogenesis of COPD and suggests that host defense mechanisms responsible for the protection of lung from respiratory pathogens are suppressed in the lungs of individuals with COPD in a broad and rather non-specific manner, indicative of fundamental defects in the innate immune system.

\section{Innate Immunity in COPD}

The lung innate immune system is comprised of five major components: the airway epithelial barrier, alveolar macrophages, dendritic cells, neutrophils, and natural killer cells (fig. 1).

\section{Airway Epithelial Barrier}

The airway epithelium, a pseudostratified layer of epithelial cells lining the tracheobronchial tree, is the initial cell population that interacts with inhaled environmental contaminants, including components of the cigarette smoke, respiratory pathogens and various toxic substances present in the air. The normal differentiated airway epithelium is composed of ciliated and mucus-producing cells, which function to remove microbes and other foreign particles via mucociliary clearance mechanism. In addition, non-mucus secretory cells produce antimicrobial and anti-inflammatory proteins, and basal cells func- tion as stem/progenitor cells to constantly renew the differentiated cell populations. Apart from the antimicrobial, pro-inflammatory and immunoregulatory potential of the airway epithelium provided through epithelial cellderived cytokines and host defense proteins, airway epithelial cells provide a physical barrier from the outside environment via tight and adherence junctions that keep adjacent epithelial cells physically connected to each other and prevent passage of microbes and xenobiotics across the epithelial layer [7].

Cigarette smoking leads to dramatic changes in the airway epithelial architecture. Among those changes are squamous metaplasia, replacement of differentiated ciliated and secretory cells with squamous cells not present in the normal airways, and mucous cell hyperplasia, which leads to airway obstruction due to increased secretion of mucus into the airway lumen [8]. Further, there are a decreased number of ciliated cells, shortening of cilia and altered ciliary beating, which together may significantly reduce the efficiency of the mucociliary elimination of respiratory pathogens $[8,9]$. Smoking-induced mucus-producing cell hyperplasia in the small airways is accompanied by loss of Clara cells, a secretory cell population enriched in the distal airways and responsible for the production of secretoglobin, surfactant proteins and other host defense factors [10]. The reduced expression of the polymeric immunoglobulin receptor/secretory component in the small airway epithelium, which normally transports secretory immunoglobulin A to the mucosal surface to sample pathogens present in the airway lumen, correlates with the severity of airflow obstruction in smokers with COPD [11]. In addition, cigarette smoke impairs airway epithelial generation of effective antimicrobial defenses via suppression of activation of the nuclear factor (NF)- $\mathrm{kB}$, a transcription factor critical for various innate immune responses [12], and inhibition of the molecular pathways necessary for interferon production in response to viral infection [5]. Moreover, smoking increases permeability of the airway epithelium [13] through broad downregulation of the transcriptional program responsible for the junctional barrier formation, which is further suppressed in COPD smokers $[7,14]$.

\section{Alveolar Macrophages}

Alveolar macrophages (AM) reside on the respiratory epithelial surface and thus are directly exposed to the outside environment. As the pulmonary representatives of the mononuclear phagocyte system, AM are responsible for a broad set of host defense functions including recognition and phagocytosis of pathogenic material and apop- 

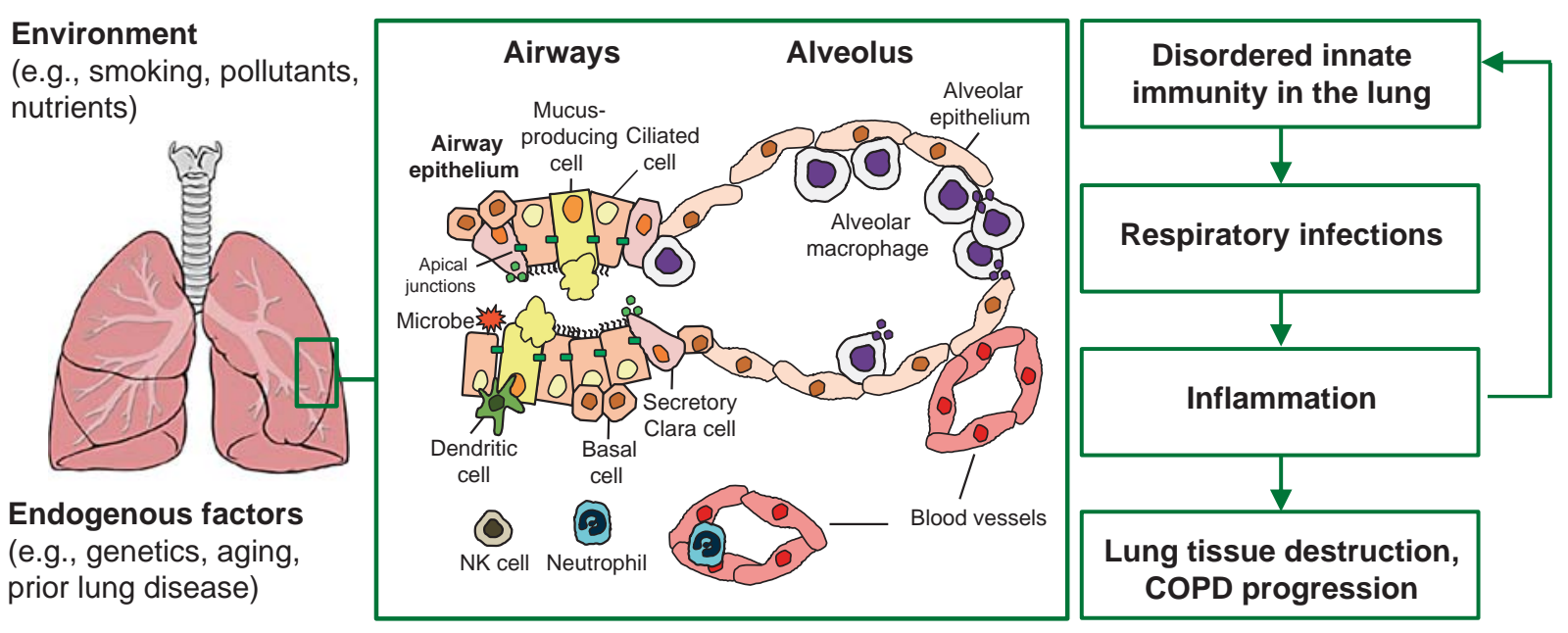

Fig. 1. The role of disordered innate immunity in COPD pathogenesis. Various environmental and endogenous factors determine the status of the innate immune system in the lung, which includes the airway epithelial barrier composed of different populations of airway epithelial cells (ciliated, mucus-producing, secretory Clara, basal cells) connected to each other via apical junctions, and host defense cells of the hematopoietic origin such as AM, dendritic cells, neutrophils, and NK cells. Chronic exposure to cigarette smoke and other harmful factors, as well as endoge-

totic cells. Depending on the nature of the stimuli, this leads to either production of pro-inflammatory cytokines and antimicrobial factors ('classical activation' or M1 polarization) or generation of anti-inflammatory and tissue remodeling factors critical for resolution of inflammation and tissue repair ('alternative activation' or M2 polarization) [15].

The numbers of AM are significantly increased in the lungs of smokers, including those with COPD, where AM accumulate in the areas of emphysematous destruction, and there is a correlation between the numbers of AM, airway obstruction and the severity of COPD [16]. A growing body of evidence suggests that increased AM number in healthy and COPD smokers is accompanied by a broad suppression of the host defense function of these cells. For example, AM isolated from individuals with COPD exhibit reduced capacity to phagocytose bacteria commonly found in the lung of individuals with COPD, such as H. influenzae [17].

Genome-wide transcriptional analysis has shown that AM isolated from healthy smokers and smokers with COPD exhibit a broad inactivation of the $\mathrm{M} 1$ polarization program critical for the host defense function, accompa- nous processes in the lung such as aging and pathological changes associated with prior diseases can suppress the host defense potential of the innate immune mechanisms in the lung, leading to increased susceptibility to respiratory infections which cause secondary inflammation and, thereby, contribute to lung tissue destruction and progressive decline in lung function in COPD patients. In addition, COPD-associated inflammation and tissue damage further suppress innate immune mechanisms in the lung.

nied by activation of various subtypes of the M2 polarization [15]. Among the innate immune genes suppressed in the AM of smokers are the type I chemokines CXCL9, CXCL11 and CCL5, inflammasome-related cytokines IL$1 \beta$ and IL-18, complement-related proteins, antimicrobial peptide cathelicidin LL-37, and a number of proteins involved in IFN- $\gamma$ signaling [15]. The suppressed M1 polarization program in the AM of smokers can result from decreased levels of IFN- $\gamma$, the major activator of the M1 program, as numbers of lung IFN- $\gamma$-producing $\mathrm{T}$ cells are reduced in smokers [18]. By contrast, the numbers of CD4+CD25+ regulatory $\mathrm{T}$ cells are increased in the lung epithelial surface of smokers [19], which can maintain an immunosuppressive microenvironment leading to AM deactivation. Another important mechanism of suppressed innate immune function of AM in patients with COPD is a decreased ability to defend against smokinginduced oxidative stress. Expression of NF-E2-related factor 2 (Nrf2), which is a key transcription factor initiating antioxidant response, is significantly reduced in COPD smokers [20], and restoration of its activity results in improved phagocytosis of $H$. influenzae and Pseudomonas aeruginosa by AM isolated from individuals with COPD [21]. 


\section{Dendritic Cells}

Dendritic cells (DC) are a specialized population of mononuclear cells responsible for recognition and uptake of pathogenic materials. Airway DC reside adjacent to epithelial cells and extend cytoplasmic protrusions to sample luminal antigens and interact with environmental signals. The DC migrate to local lymphoid tissues, such as regional lymph nodes or mucosal lymphoid aggregates, for presentation of the processed antigens to lymphocytes, initiating adaptive immune response to pathogens. Increased number of DC expressing langerin, a marker of immature DC, has been found in the small airways of patients with COPD [22]. The number of mature $\mathrm{DC}$, as defined by the expression of the maturation marker CD83, is significantly reduced in the small airways and alveoli of smokers with COPD [23]. COPD smokers have 100-fold fewer DC in the bronchial epithelium compared to healthy controls, and the numbers of airway intraepithelial DC normalize following smoking cessation [24]. Consistent with this, cigarette smoke exposure decreased the frequency and activation status of lung DC and reduced the capacity of DC to stimulate T cells and initiate antiviral immune responses in animal studies [25].

\section{Neutrophils}

By contrast to AM and DC, neutrophils are innate immune cells present in the lung tissue under steady-state conditions in small numbers, but rapidly migrate to the sites of infection or injury in response to a distinct set of pro-inflammatory chemoattractants released by epithelial cells and AM. Once in the lung parenchyma, neutrophils phagocytose bacteria and release antimicrobial factors and highly reactive oxidants that inactivate pathogens. However, these mediators can also damage host tissue if the neutrophil-mediated inflammatory response is not properly controlled.

In COPD, the neutrophil-mediated response is rather directed against the lung tissue itself, as increased number of neutrophils observed in COPD is not accompanied by effective elimination of bacteria but instead, contributes to the severity of airway obstruction and emphysema [26]. In the small airways of individuals with severe COPD, neutrophils are found within the epithelial layer, and the number of neutrophils correlates with epithelial proliferation and airflow limitation [27]. Neutrophil elastase, one of the major neutrophil-derived products in the lungs of individuals with COPD, can cause many pathological features of COPD, including emphysematous destruction of lung tissue [26].
There is evidence that the host defense function of neutrophils is impaired in COPD. Neutrophils isolated from the blood of individuals with moderate to severe COPD showed decreased chemotaxis in response to classical chemoattractants such as bacterial protein $\mathrm{N}$-formyl-Met-Leu-Phe (fMLP) and the pro-inflammatory cytokine interleukin (IL)-8, with a correlation between the reduced chemotaxis of neutrophils to fMLP and the degree of airflow limitation [28]. Further, neutrophils from individuals with COPD migrate faster than those from healthy subjects, but the accuracy of migration toward known chemoattractants, such as FMLP and IL-8, is markedly reduced [29]. Cigarette smoke components can inhibit the oxidative burst and phagocytic capacities of neutrophils $[26,30]$.

\section{Natural Killer Cells}

Natural killer (NK) cells are innate immune cells that sense virus infected, transformed or stressed cells in an antigen-non-specific manner. NK cells secrete an array of cytokines, including IFN- $\gamma$, TNF- $\alpha$, and IL-12 necessary for activation of other immune cells, helping to destroy virus infected and transformed cells via secretion of perforin and other cytotoxic factors. Smokers have marked depression of NK cell activity [31] and there is recent evidence that exposure of human NK cells to cigarette smoke inhibits IFN- $\gamma$ and TNF- $\alpha$ production, perforin expression and cytotoxic activity of these cells [31]. While the numbers and function of NK cells in the lung of healthy and COPD smokers are controversial, reduced NK cell activity has been observed in the blood of individuals with COPD [32].

\section{Inflammation in COPD}

COPD has been traditionally viewed as a chronic inflammatory disease, which develops in response to noxious particles or gas, most commonly from tobacco smoking [1]. This view has been supported by observations of increased numbers of classical inflammatory cell types, such as neutrophils and AM, in the lungs of smokers, including those with COPD, correlating with disease severity $[1,16,26]$. As summarized above, the host defense potential of these cells in individuals with COPD is significantly reduced in a smoking-dependent manner. Thus, smoking-induced inflammation is unique in the way that accumulation of inflammatory cells in the lung is not coupled to the effective innate immunity but, instead, leads to progressive lung tissue injury. In addition, 
genome-wide transcription studies show that there is a broad suppression of the transcriptional programs related to inflammation in the small airway epithelium and AM of smokers with COPD during exacerbation-free periods $[15,33]$.

Defective innate immunity in the lungs of smokers likely contributes to the increased frequency of bacterial and viral infections, a common cause of COPD exacerbations, and facilitates secondary inflammation caused by respiratory pathogens [3]. For example, in response to rhinovirus infection, a common cause of COPD exacerbations, airway epithelial cells of individuals with COPD produce elevated levels of chemokines CXCL1, 5, and 8 in association with high viral load [5]. Indeed, there is extensive data showing increased expression of inflammatory genes, such as chemokines important for the recruitment of leukocytes, including neutrophils, by epithelial cells of COPD smokers in association with disease severity [34]. This observation is consistent with increased number of neutrophils in the lungs of COPD patients infected with this virus [6], accompanied by defective production of interferons necessary for effective antiviral defense [5]. Viral infection of the lung further suppresses the lung innate immune system via degradation of antimicrobial and anti-inflammatory proteins such as secretory leukoprotease inhibitor (SLPI) and lactoferrin, leading to secondary bacterial infection [35]. In turn, bacterial pathogens commonly colonizing the lung of individuals with COPD, such as $H$. influenzae and $P$. aeruginosa, can further promote inflammation and facilitate viral infection by increasing expression of the rhinovirus receptor ICAM-1 on airway epithelial cells [5]. Thus, chronic inflammation in COPD is initiated and maintained by complex relationships of the lung cells with respiratory pathogens, resulting in a broad suppression of lung innate immune mechanisms.

Smoking- and COPD-associated changes in the architecture of the airway epithelial barrier can also contribute to lung inflammation. Loss of Clara cells in the small airways of smokers [10] leads to decreased production of anti-inflammatory protein secretoglobin 1A1 (also known as Clara cell protein). Squamous metaplasia, a common histologic lesion in the airway epithelium of individuals with COPD [8], is associated with increased production of pro-inflammatory cytokines IL- $1 \alpha$ and IL$1 \beta[36]$ and decreased expression of antimicrobial factors, such as SLPI, which normally limits the inflammatory damage of the lung tissue by inhibiting neutrophil elastase [37]. Further, disorganization of the junctional bar- rier in the airway of COPD smokers results in increased permeability of the airway epithelium $[7,13,14]$, which may allow microbial products or cigarette smoke components to diffuse through the epithelial layer and activate inflammatory cells in the airway mucosa.

\section{Relationships between Innate Immunity, COPD and Aging}

The broad suppression of the innate immunity in smokers and individuals with COPD resembles the immunosenescence phenotype, a general decrease in the host defense potential of various immune cells, associated with aging, accompanied by an increased susceptibility to infections and cancer [38]. Although aging-related changes in human lung innate immunity have not been studied in detail, aging is generally associated with alterations in the whole network of innate immune cells with a pattern similar to that in COPD (table 1). There is evidence that aging is associated with decreased epithelial barrier function [39], abnormalities in respiratory cilia structure and function [40], and reduced antimicrobial/anti-inflammatory protein production by epithelial cells, including SLPI [41]. Similar to COPD, aging is associated with increased number of phagocytes, both monocytes/macrophages and neutrophils, accompanied by significant suppression of the host defense function of these cells, such as decreased phagocytotic potential of tissue-resident macrophages, inefficient chemotaxis and decreased bactericidal functions of neutrophils, and alterations in the number and activity of DC and NK cells [38]. Age-associated immunosuppression is commonly accompanied by chronic low-grade inflammation, a phenomenon described as 'inflamm-aging' [38], similar to COPD, in which respiratory infections, developing as a result of impaired host defense in the lung, can elicit secondary inflammation [3].

Several factors associated with COPD pathogenesis can explain why the innate immune system in this disease acquires aging-like characteristics. Since development of pathologic changes in the lung resulting in reduction of lung function progresses very slowly over several decades of cigarette smoking, individuals with COPD develop symptoms when they are $>40$ years of age [1]. Thus, similarities in patterns of the innate immunity dysregulation in COPD smokers and healthy elderly people can be due to both the overall older age of COPD smokers compared to the general population together with the chronic immunosuppressive effect of cigarette smoking. Smoking is 
Table 1. Innate immunity changes associated with COPD and aging: similarities and potential therapeutic strategies

\begin{tabular}{|c|c|c|c|}
\hline \multicolumn{4}{|l|}{ Epithelium } \\
\hline Junctional barrier integrity & $\downarrow$ & $\downarrow$ & anti-EGF/EGFR \\
\hline Ciliated cell integrity and function & $\downarrow$ & $\downarrow$ & augmentation of SLPI \\
\hline Antimicrobial factor expression & $\downarrow$ & $\downarrow$ & glutathione aerosol \\
\hline \multicolumn{4}{|l|}{ Macrophage } \\
\hline Antimicrobial factor expression & $\downarrow$ & $\downarrow$ & macrolide antibiotics \\
\hline \multicolumn{4}{|l|}{ Dendritic cell } \\
\hline Number & $\downarrow$ & $\downarrow \uparrow$ & augmentation of elafin \\
\hline Maturation & $\downarrow$ & $\downarrow$ & \\
\hline Capacity to activate $\mathrm{T}$ cells & $\downarrow$ & $\downarrow$ & \\
\hline \multicolumn{4}{|l|}{ Neutrophil } \\
\hline Antibacterial potential & $\downarrow$ & $\downarrow$ & antioxidants (glutathione) \\
\hline \multicolumn{4}{|l|}{ NK cells } \\
\hline Number & $\downarrow \uparrow$ & $\downarrow$ & glycophosphopeptical \\
\hline Activity & $\downarrow$ & $\downarrow$ & zinc supplementation \\
\hline
\end{tabular}

associated with induction of senescence of the structural cells of the lung [42], and it likewise may cause premature aging of the innate immune cells. Further, similar to aging-associated immunosenescence that contributes to increased susceptibility of the elderly to malignancies, suppression of the innate immune mechanisms in COPD patients may explain why COPD is associated with increased risk for the development of lung cancer [1]. In addition, telomere shortening in circulating leukocytes has been observed in COPD patients independent from smoking status in association with increased expression of inflammatory markers [43], suggesting that disease-specific factors may be responsible for premature aging of immune cells and providing potential mechanism for dysregulation of innate immune system in COPD patients who never smoked.

\section{Therapeutic Perspectives}

In the context that COPD is associated with a broad, smoking-induced suppression of the innate immune system, effective prevention of COPD progression should include strategies aimed at the normalization of the disordered components of innate immunity. Since multiple elements of the innate immunity are impaired in COPD and may represent parts of the common pathologic process initiated by cigarette smoking, prospective therapies should be directed at correcting a number of disordered elements at the same time, by targeting common pathologic mechanisms. Certainly, smoking cessation should be considered one of the primary approaches, as most of the altered innate immune features in COPD represent the consequence of the immunosuppressive effect of cigarette smoking. For COPD patients having other risk factors, which can potentially alter innate immune mechanisms in addition to or independent from cigarette smoking, such as exposure to occupational pollutants, alcoholism, obesity, chronic renal failure, insufficient physical activity, and altered micronutrient status [1], specific measures related to the relevant co-factors of disease pathogenesis should be considered as a primary therapeutic strategy. In addition, COPD therapies such as glucocorticoids, oxygen supplementation and methyxanthines have a potential to suppress innate immunity $[44,45]$, suggesting that therapeutic strategies to aug- 
ment innate defense mechanisms in COPD patients should aim at compensation of both disease-related and potential therapy-associated alterations in the host defense system.

\section{Correction of Epithelial Barrier and Defense}

Mechanisms

Based on the knowledge that signaling via epidermal growth factor receptor (EGFR) mediates smoking-induced disruption of the airway epithelial barrier integrity [14], therapies aimed at local control of the EGFR activity in the airways may be beneficial to improve host defense function of the airway epithelium in COPD smokers. Another strategy could be augmenting epithelial-derived host defense proteins with antimicrobial and/or anti-inflammatory properties significantly decreased in the COPD lung, such as SLPI [46]. In addition, physical exercise can help remove excessive mucus from the airways and, thereby, improve the physiological status of the mucociliary barrier.

\section{Augmentation of Antioxidant Response}

The ability to maintain appropriate antioxidant response by lung cells is critical for the endogenous protection against smoking-induced oxidative stress. NF-E2related factor (Nrf2), a key transcription factor that induces expression of numerous antioxidant genes, is downregulated in the AM of smokers and individuals with COPD in association with aging [20]. Pharmacological reactivation of Nrf2 by sulforaphane restored the ability of AM from individuals with COPD to recognize and phagocytose the COPD-relevant bacteria $H$. influen$z a e$ and $P$. aeruginosa [21]. Another strategy to augment antioxidant defense in the lungs of COPD patients can be aerosolization of glutathione, a potent antioxidant which has been shown to improve smoking-suppressed host defense response of airway epithelial cells to $H$. influenzae [12].

\section{Immunomodulation}

Since both infection and inflammation play significant roles in the progression of COPD, therapies that simultaneously target these components of COPD pathogenesis could be particularly useful. The macrolide antibiotic azithromycin, which in addition to its antibacterial effects has anti-inflammatory properties, has been shown to be effective in prevention of COPD exacerbations [47] and restoration of the defective phagocytic function of AM in COPD [48]. Inhibition of the phosphoinositide 3-kinase (PI3K), one of the key mediators of pathologic processes in the airways of smokers, could be beneficial in restoration of the altered innate defense functions in COPD patients, such as neutrophil chemotaxis [29]. Defective phagocytosis and NK cell activity in COPD can be restored by immunomodulator glycophosphopeptical [32]. Therapeutic overexpression of elafin, an epithelium- and innate immune cell-derived antimicrobial peptide and elastase inhibitor, can protect from emphysematous lung tissue injury by neutrophil elastase, and, in addition, augment host defense through potentiation of lung DC activation [49]. Zinc supplementation, which has the potential to improve NK cell function while reducing systemic inflammatory markers in healthy elderly [50], could be a candidate approach to normalize disordered innate immunity in COPD. A number of promising anti-inflammatory and immunomodulatory therapeutic strategies, such as drugs that interfere with adhesion molecules, cytokine signaling and lipid metabolism, have become the focus of extensive investigation [47], although their potential to augment function of specific components of innate immune system suppressed in the lungs of COPD patients remains largely unknown.

In summary, COPD can be viewed as a chronic lung disease with a broad smoking-dependent suppression or premature aging of various components of the innate immune system. This may underlie the increased frequency of respiratory infections and secondary inflammation, the major factors that drive progression of the disease (fig. 1). Therefore, effective prevention of COPD development should include therapeutic strategies aimed at normalization of the disordered components of the innate immune system. Given remarkable heterogeneity of COPD-associated clinical and biologic phenotypes [1, 33], these therapeutic strategies should be designed in a personalized manner, i.e. based on the knowledge of particular cellular and molecular alterations in the innate immune system in each individual patient.

\section{Acknowledgements}

These studies were supported, in part, by 1R01HL107882, P50 HL084936 and NPRP 5-400-3-107; R.S. is supported, in part, by The Parker B. Francis Foundation. 


\section{References}

-1 Decramer M, Janssens W, Miravitlles M: Chronic obstructive pulmonary disease. Lancet 2012;379:1341-1351.

-2 Lamprecht B, McBurnie MA, Vollmer WM, Gudmundsson G, Welte T, NizankowskaMogilnicka E, Studnicka M, Bateman E, Anto JM, Burney P, Mannino DM, Buist SA: COPD in never smokers: results from the population-based burden of obstructive lung disease study. Chest 2011;139:752-763.

$\checkmark 3$ Sethi S, Murphy TF: Infection in the pathogenesis and course of chronic obstructive pulmonary disease. N Engl J Med 2008;359: 2355-2365.

4 Cabrera-Rubio R, Garcia-Nunez M, Seto L, Anto JM, Moya A, Monso E, Mira A: Microbiome diversity in the bronchial tracts of patients with chronic obstructive pulmonary disease. J Clin Microbiol 2012;50:35623568.

5 Sajjan US: Susceptibility to viral infections in chronic obstructive pulmonary disease: role of epithelial cells. Curr Opin Pulm Med 2013; 19:125-132.

-6 Mallia P, Message SD, Gielen V, Contoli M, Gray K, Kebadze T, Aniscenko J, Laza-Stanca V, Edwards MR, Slater L, Papi A, Stanciu LA, Kon OM, Johnson M, Johnston SL: Experimental rhinovirus infection as a human model of chronic obstructive pulmonary disease exacerbation. Am J Respir Crit Care Med 2011;183:734-742.

7 Shaykhiev R, Otaki F, Bonsu P, Dang DT, Teater M, Strulovici-Barel Y, Salit J, Harvey BG, Crystal RG: Cigarette smoking reprograms apical junctional complex molecular architecture in the human airway epithelium in vivo. Cell Mol Life Sci 2011;68:877-892.

$>8$ Auerbach O, Forman JB, Gere JB, Kassouny DY, Muehsam GE, Petrick TG, Smolin HJ, Stout AP: Changes in the bronchial epithelium in relation to smoking and cancer of the lung; a report of progress. N Engl J Med 1957; 256:97-104

$>9$ Leopold PL, O’Mahony MJ, Lian XJ, Tilley AE, Harvey BG, Crystal RG: Smoking is associated with shortened airway cilia. PLoS One 2009; 4:e8157.

-10 Lumsden AB, McLean A, Lamb D: Goblet and Clara cells of human distal airways: evidence for smoking induced changes in their numbers. Thorax 1984;39:844-849.

11 Pilette C, Godding V, Kiss R, Delos M, Verbeken E, Decaestecker C, De Paepe K, Vaerman JP, Decramer M, Sibille Y: Reduced epithelial expression of secretory component in small airways correlates with airflow obstruction in chronic obstructive pulmonary disease. Am J Respir Crit Care Med 2001;163: 185-194.

$>12$ Manzel LJ, Shi L, O’Shaughnessy PT, Thorne PS, Look DC: Inhibition by cigarette smoke of nuclear factor- $\kappa \mathrm{B}$-dependent response to bacteria in the airway. Am J Respir Cell Mol Biol 2011;44:155-165.
13 Kennedy SM, Elwood RK, Wiggs BJ, Pare PD, Hogg JC: Increased airway mucosal permeability of smokers. Relationship to airway reactivity. Am Rev Respir Dis 1984;129:143148.

14 Heijink IH, Brandenburg SM, Postma DS, van Oosterhout AJ: Cigarette smoke impairs airway epithelial barrier function and cell-cell contact recovery. Eur Respir J 2012;39:419428.

15 Shaykhiev R, Krause A, Salit J, StruloviciBarel Y, Harvey BG, O'Connor TP, Crystal RG: Smoking-dependent reprogramming of alveolar macrophage polarization: implication for pathogenesis of chronic obstructive pulmonary disease. J Immunol 2009;183: 2867-2883.

16 Barnes PJ: Alveolar macrophages as orchestrators of COPD. COPD 2004;1:59-70.

-17 Taylor AE, Finney-Hayward TK, Quint JK, Thomas CM, Tudhope SJ, Wedzicha JA, Barnes PJ, Donnelly LE: Defective macrophage phagocytosis of bacteria in COPD. Eur Respir J 2010;35:1039-1047.

18 Hagiwara E, Takahashi KI, Okubo T, Ohno S, Ueda A, Aoki A, Odagiri S, Ishigatsubo Y: Cigarette smoking depletes cells spontaneously secreting $\mathrm{Th}(1)$ cytokines in the human airway. Cytokine 2001;14:121-126.

19 Smyth LJ, Starkey C, Vestbo J, Singh D: CD4regulatory cells in COPD patients. Chest 2007;132:156-163.

20 Suzuki M, Betsuyaku T, Ito Y, Nagai K, Nasuhara Y, Kaga K, Kondo S, Nishimura M: Down-regulated NF-E2-related factor 2 in pulmonary macrophages of aged smokers and patients with chronic obstructive pulmonary disease. Am J Respir Cell Mol Biol 2008; 39:673-682.

21 Harvey CJ, Thimmulappa RK, Sethi S, Kong X, Yarmus L, Brown RH, Feller-Kopman D, Wise R, Biswal S: Targeting Nrf2 signaling improves bacterial clearance by alveolar macrophages in patients with COPD and in a mouse model. Sci Transl Med 2011;3: $78 \mathrm{ra} 32$.

22 Van Pottelberge GR, Bracke KR, Demedts IK, De Rijck K, Reinartz SM, van Drunen CM, Verleden GM, Vermassen FE, Joos GF, Brusselle GG: Selective accumulation of Langerhans-type dendritic cells in small airways of patients with COPD. Respir Res 2010;11:35.

23 Tsoumakidou M, Koutsopoulos AV, Tzanakis N, Dambaki K, Tzortzaki E, Zakynthinos S, Jeffery PK, Siafakas NM: Decreased small airway and alveolar CD83+ dendritic cells in COPD. Chest 2009;136:726-733.

24 Rogers AV, Adelroth E, Hattotuwa K, Dewar A, Jeffery PK: Bronchial mucosal dendritic cells in smokers and ex-smokers with COPD: an electron microscopic study. Thorax 2008; 63:108-114.
25 Robbins CS, Dawe DE, Goncharova SI, Pouladi MA, Drannik AG, Swirski FK, Cox G, Stampfli MR: Cigarette smoke decreases pulmonary dendritic cells and impacts antiviral immune responsiveness. Am J Respir Cell Mol Biol 2004;30:202-211.

26 Hoenderdos K, Condliffe A: The neutrophil in COPD: too little too late, or too much too soon? Am J Respir Cell Mol Biol, in press.

27 Pilette C, Colinet B, Kiss R, Andre S, Kaltner H, Gabius HJ, Delos M, Vaerman JP, Decramer M, Sibille Y: Increased galectin-3 expression and intra-epithelial neutrophils in small airways in severe COPD. Eur Respir J 2007;29: 914-922.

28 Yoshikawa T, Dent G, Ward J, Angco G, Nong G, Nomura N, Hirata K, Djukanovic R: Impaired neutrophil chemotaxis in chronic obstructive pulmonary disease. Am J Respir Crit Care Med 2007;175:473-479.

29 Sapey E, Stockley JA, Greenwood H, Ahmad A, Bayley D, Lord JM, Insall RH, Stockley RA: Behavioral and structural differences in migrating peripheral neutrophils from patients with chronic obstructive pulmonary disease. Am J Respir Crit Care Med 2011;183:1176-1186.

30 Zappacosta B, Persichilli S, Minucci A, Fasanella S, Scribano D, Giardina B, De Sole P: Effect of cigarette smoke extract on the polymorphonuclear leukocytes chemiluminescence: influence of a filter containing glutathione. Luminescence 2005;20:73-75.

31 Mian MF, Lauzon NM, Stampfli MR, Mossman KL, Ashkar AA: Impairment of human NK cell cytotoxic activity and cytokine release by cigarette smoke. J Leukoc Biol 2008;83: 774-784.

32 Prieto A, Reyes E, Bernstein ED, Martinez B, Monserrat J, Izquierdo JL, Callol L, de Lucas P, Alvarez-Sala R, Alvarez-Sala JL, Villarrubia VG, Alvarez-Mon M: Defective natural killer and phagocytic activities in chronic obstructive pulmonary disease are restored by glycophosphopeptical (inmunoferon). Am J Respir Crit Care Med 2001;163:1578-1583.

-33 Tilley AE, O'Connor TP, Hackett NR, Strulovici-Barel Y, Salit J, Amoroso N, Zhou XK, Raman T, Omberg L, Clark A, Mezey J, Crystal RG: Biologic phenotyping of the human small airway epithelial response to cigarette smoking. PLoS One 2011;6:e22798.

34 Thorley AJ, Tetley TD: Pulmonary epithelium, cigarette smoke, and chronic obstructive pulmonary disease. Int J Chron Obstruct Pulmon Dis 2007;2:409-428.

35 Mallia P, Footitt J, Sotero R, Jepson A, Contoli M, Trujillo-Torralbo MB, Kebadze T, Aniscenko J, Oleszkiewicz G, Gray K, Message SD, Ito K, Barnes PJ, Adcock IM, Papi A, Stanciu LA, Elkin SL, Kon OM, Johnson M, Johnston SL: Rhinovirus infection induces degradation of antimicrobial peptides and secondary bacterial infection in chronic obstructive pulmonary disease. Am J Respir Crit Care Med 2012;186:1117-1124. 
36 Araya J, Cambier S, Markovics JA, Wolters P, Jablons D, Hill A, Finkbeiner W, Jones K, Broaddus VC, Sheppard D, Barzcak A, Xiao Y, Erle DJ, Nishimura SL: Squamous metaplasia amplifies pathologic epithelial-mesenchymal interactions in COPD patients. J Clin Invest 2007;117:3551-3562.

37 Aarbiou J, van Schadewijk A, Stolk J, Sont JK, de Boer WI, Rabe KF, van Krieken JH, Mauad T, Hiemstra PS: Human neutrophil defensins and secretory leukocyte proteinase inhibitor in squamous metaplastic epithelium of bronchial airways. Inflamm Res 2004;53:230-238.

38 Fulop T, Larbi A, Kotb R, de Angelis F, Pawelec G: Aging, immunity, and cancer. Discov Med 2011;11:537-550.

-39 Ghadially R, Brown BE, Sequeira-Martin SM, Feingold KR, Elias PM: The aged epidermal permeability barrier. Structural, functional, and lipid biochemical abnormalities in humans and a senescent murine model. J Clin Invest 1995;95:2281-2290.

40 Ho JC, Chan KN, Hu WH, Lam WK, Zheng L, Tipoe GL, Sun J, Leung R, Tsang KW: The effect of aging on nasal mucociliary clearance, beat frequency, and ultrastructure of respiratory cilia. Am J Respir Crit Care Med 2001; 163:983-988.
1 Shugars DC, Watkins CA, Cowen HJ: Salivary concentration of secretory leukocyte protease inhibitor, an antimicrobial protein, is decreased with advanced age. Gerontology 2001;47:246-253.

42 Aoshiba K, Nagai A: Senescence hypothesis for the pathogenetic mechanism of chronic obstructive pulmonary disease. Proc Am Thorac Soc 2009;6:596-601.

43 Savale L, Chaouat A, Bastuji-Garin S, Marcos E, Boyer L, Maitre B, Sarni M, Housset B, Weitzenblum E, Matrat M, Le CP, Rideau D, Boczkowski J, Dubois-Rande JL, Chouaid C, Adnot S: Shortened telomeres in circulating leukocytes of patients with chronic obstructive pulmonary disease. Am J Respir Crit Care Med 2009;179:566-571.

44 Baleeiro CE, Wilcoxen SE, Morris SB, Standiford TJ, Paine R III: Sublethal hyperoxia impairs pulmonary innate immunity. J Immunol 2003;171:955-963.

45 Kambayashi T, Wallin RP, Ljunggren HG: cAMP-elevating agents suppress dendritic cell function. J Leukoc Biol 2001;70:903-910.
46 Vogelmeier C, Buhl R, Hoyt RF, Wilson E, Fells GA, Hubbard RC, Schnebli HP, Thompson RC, Crystal RG: Aerosolization of recombinant SLPI to augment antineutrophil elastase protection of pulmonary epithelium. J Appl Physiol 1990;69:1843-1848.

47 Cazzola M, Page CP, Calzetta L, Matera MG: Emerging anti-inflammatory strategies for COPD. Eur Respir J 2012;40:724-741.

48 Hodge S, Hodge G, Jersmann H, Matthews G, Ahern J, Holmes M, Reynolds PN: Azithromycin improves macrophage phagocytic function and expression of mannose receptor in chronic obstructive pulmonary disease. Am J Respir Crit Care Med 2008;178:139148.

49 Roghanian A, Williams SE, Sheldrake TA, Brown TI, Oberheim K, Xing Z, Howie SE, Sallenave JM: The antimicrobial/elastase inhibitor elafin regulates lung dendritic cells and adaptive immunity. Am J Respir Cell Mol Biol 2006;34:634-642.

50 Mariani E, Neri S, Cattini L, Mocchegiani E, Malavolta M, Dedoussis GV, Kanoni S, Rink L, Jajte J, Facchini A: Effect of zinc supplementation on plasma IL- 6 and MCP-1 production and NK cell function in healthy elderly: interactive influence of +647 MT1a and -174 IL-6 polymorphic alleles. Exp Gerontol 2008;43:462-471. 